\title{
Espaços e interações coletivas: da intenção do artista à ação do espectador
}

Fernanda de Oliveira Gomes; Programa de Pós Graduação em Comunicação, Escola de Comunicação da Universidade Federal do Rio de Janeiro, Rio de Janeiro, RJ; Email: <infernanda@yahoo.com>.

Resumo

Este trabalho busca lançar uma luz sobre o papel dos espaços em suas diversas configurações nos processos de comunicação artística, levando em consideração as relações possíveis a partir da inserção dos indivíduos em sistemas dispositivos que privilegiam a composição de imagens em tempo real e a formação de coletividades efêmeras. Nas diversas experimentações com imagens em movimento, identificadas no contexto contemporâneo, podemos identificar algumas propostas que entram em diversos tipos de interações e contaminações, não só com os espectadores, mas também com os espaços, culturas e contextos nos quais são inseridas. Geralmente os artistas que fazem parte deste recorte são identificados como verdadeiros agentes, principalmente no processo de produção e recepção de instalações interativas expostas em espaços públicos. Cada vez mais os artistas se conscientizam dos modos de produção e das relações humanas possibilitadas pelas técnicas de sua época. A arte torna estes modos de produção muito mais visíveis, possibilitando estender suas consequências na vida cotidiana.

Palavras-chave: Espaço, Imagem, Interação, Dispositivo.

\section{O contemporâneo e suas experimentações}

Nas diversas experimentações com imagens em movimento, identificadas no contexto contemporâneo, podemos identificar algumas propostas que entram em diversos tipos de interações e contaminações, não só com os espectadores, mas também com os espaços, culturas e contextos nos quais são inseridas. Geralmente os artistas que fazem parte deste recorte são identificados como verdadeiros agentes, principalmente no processo de produção e recepção de instalações interativas expostas em espaços públicos. 
O artista mexicano Rafael Lozano-Hemmer pode ser apontado como um exemplo de artista agente, que leva diversas obras para os espaços públicos, possibilitando trocas entre espectadores, seus corpos, seus gestos, imagens e espaços, em propostas que apresentam grandes complexidades técnicas. Sua obra Body Movies, transforma o espaço público em uma espécie de teatro de sombras e imagens a partir de projeções de corpos em grande escala. Diversos retratos fotográficos, previamente tirados nas ruas das cidades onde o projeto é apresentado, são mostrados através de projetores controlados roboticamente. Os retratos aparecem somente dentro das sombras projetadas pelas pessoas que interagem com a instalação. Ao perceberem suas sombras projetadas em grande escala, estas pessoas começam a se movimentar de forma performática, evidenciando seus gestos umas para as outras. Esta obra proporciona então uma interação entre corpo e espaço público, entre corpo e imagem e entre corpos de transeuntes que se transformam em espectadores e em performers a partir do momento em que se relacionam com os dispositivos espaciais e tecnológicos.

Na obra posterior, Under Scan, o artista passa a projetar vídeoretratos em pisos de praças. Em um primeiro momento, estes retratos não podem ser vistos, já que estão apagados por um potente projetor. Quando caminham na área coberta pelo sistema dispositivo, as pessoas descobrem os retratos, que são projetados em suas sombras. As sequências de vídeo começam com as pessoas retratadas olhando para um lado. A partir do momento em que aparecem projetados nas sombras dos transeuntes, os retratos se movem e se voltam para eles. Começa então um processo de interação performática entre as pessoas que produzem as sombras e as pessoas previamente gravadas. Devido à sua complexidade, o projeto teve apoio de um grande número de desenvolvedores. Porém, os dispositivos praticamente não são visíveis e a experiência se torna extremamente orgânica. 
Produções artísticas e midiáticas explicitam cada vez mais um caráter experimental próprio da contemporaneidade. A dissolução atual dos limites entre diferentes espaços de representação (cinema, vídeo, galeria), está implicitamente relacionada com a dissolução de papéis (espectador, diretor, ator) e de posicionamentos (tela, palco, plateia). Por isso identificamos cada vez mais produções realizadas com os mais variados tipos de equipamentos, por indivíduos dos mais diversos perfis, e, segundo o foco desta proposta, em espaços que não foram previamente destinados para suas exibições.

\section{Sociedades, imagens e relações}

A partir da perspectiva de Flusser (2008), podemos afirmar que o mundo antes conhecido, vivenciado e valorizado pelas linhas escritas passou a ser dominado pelas superfícies imaginadas. Além de exercer influências sobre as mensagens, as constantes mutações nas estruturas da mediação também provocam mutações nas vivências, conhecimentos e valores. "O mundo não se apresenta mais enquanto linha, processo, acontecimento, mas enquanto plano, cena, contexto" (FLUSSER, 2008, p. 15). A nova estrutura social que está se consolidando, a da sociedade informática, organiza as pessoas em torno de imagens, exigindo novo enfoque sociológico e novos critérios.

Cada vez mais os artistas se conscientizam dos modos de produção e das relações humanas possibilitadas pelas técnicas de sua época. A arte torna estes modos de produção muito mais visíveis, possibilitando estender suas consequências na vida cotidiana. De acordo com Bourriaud (2006), a tecnologia só interessa ao artista na medida em que pode colocar os possíveis efeitos em perspectiva. A função da arte é a de se apropriar dos hábitos de percepção e de comportamento induzidos pelo complexo técnico-industrial para transformá-los em possibilidades de vida. Ou seja, apropriar-se da técnica com o fim de criar novas maneiras de pensar, viver e de ver. 
Chegamos então aos modelos experimentais e participativos, que substituem a concepção racionalista da modernidade e as relações humanas submetidas ao autoritarismo. Aqui se origina a obra de arte que Bourriaud define como arte relacional. As obras já não têm como meta formar realidades imaginárias ou utópicas, mas sim constituir modos de existências ou modelos de ação dentro do real já existente. Portanto, o que se buscam são as interações humanas, seu contexto social e a obra em processo. O autor afirma que o mundo da arte, como qualquer outro campo social, é essencialmente relacional na medida em que apresenta um sistema de posturas diferenciadas. A arte é um sistema altamente cooperativo e a densa rede de interconexões entre seus atores implica que tudo o que acontece é resultado contínuo dos papéis que vão se delineando. Segundo o autor, se a estrutura interna do mundo da arte desenha efetivamente um jogo limitado do possível, uma segunda ordem de relações externas produzem e legitimam a ordem das relações internas. A rede arte é porosa e são as relações estabelecidas com o conjunto dos campos de produção que determinam sua evolução. Estas características fazem com que os procedimentos e efeitos artísticos se aproximem dos procedimentos e efeitos das produções midiáticas.

A arte, feita da mesma matéria que as trocas sociais, ocupa um lugar particular na produção coletiva. Uma obra de arte possui uma qualidade que a diferencia dos demais produtos da atividade humana: sua relativa transparência social. Quando bem sucedida, essa obra ultrapassa sua simples presença no espaço, pois se abre para o diálogo, para a discussão, para um processo temporal que se desenvolve no aqui e no agora, para essa forma de expressão humana que Marcel Duchamp chamava de coeficiente da arte.

Na visão de Flusser (2008), a sociedade se constitui como um conjunto de comunidades de jogadores. Nesse contexto 0 artista deixa de ser visto como criador e passa a ser visto como 
um jogador que brinca com pedaços disponíveis de informação. Segundo o autor esta é precisamente a definição do termo diálogo: troca de fragmentos disponíveis de informação. No entanto, o artista brinca com o propósito de produzir informação nova, participando dos diálogos com o objetivo de produzir algo imprevisto. O método utilizado nesse jogo não é o de uma inspiração qualquer, mas sim o do diálogo com os outros e consigo mesmo: "um diálogo que lhe permita elaborar informação nova junto com informações recebidas ou com informações já armazenadas" (FLUSSER, 2008, pág. 93).

Em uma perspectiva relacional, marcada pela interlocução, as interações que se dão por meio de dispositivos são vistas como processos de influências mútuas que os participantes exercem uns sobre os outros na troca comunicativa. Processos interativos vão ao encontro do jogo de reconhecimento recíproco do cotidiano e à produção de interpretações, construção de modelos mentais, paradigmas, perspectivas, crenças e pontos de vistas constituídos de elementos cognitivos.

\section{Considerações sobre o espaço e a sociabilidade}

Michel de Certau (1997) busca relacionar lugar e espaço, adotando a distinção semiótica que Saussure criou entre a língua e a prática, ou seja, a distinção entre a linguagem e a expressão. Dessa forma, Certau propõe que o espaço é o "lugar praticado". O lugar é o acordo que se estabelece entre os elementos que são distribuídos em relações de coexistência. O espaço ocorre como efeito produzido pelas operações que o definem e que o situam. Na relação com o lugar, o espaço é como a palavra quando é falada, situada no presente e modificada pelas transformações causadas por sucessivos contextos. O espaço, como o "lugar praticado", admite a imprevisibilidade. Se o espaço é como a palavra quando é falada, então um lugar poderá ser redefinido em sucessivos, múltiplos e até irreconciliáveis espaços. Para Certau, a cidade está sempre nessa condição transitória, 
produzindo uma consciência de performance contínua do lugar. $O$ ato de mover-se pela cidade já cria uma sensação de experiência social transitória.

A especificidade de um lugar pode tomar forma a partir das relações entre as práticas espaciais. Lefebvre (2003) apontou o vivido, o percebido e o imaginado. Quais são as fronteiras? E como propostas artísticas e comunicacionais podem explorálas? As inter-relações dessas ordens espaciais privilegiam a posição do espectador e seu processo de recepção. E é a paisagem urbana que oferece uma profusão e uma complexidade de signos e espaços onde as condições de recepção e leitura podem ser trabalhadas de inúmeras formas.

O indivíduo que está em relação no cotidiano é produzido no ato de afetar e ser afetado pelo outro através de materiais significantes, com os quais lida diariamente. Ele está constantemente susceptível ao acontecimento e ao imprevisível. O interesse aqui é entender o cotidiano como palco de oscilações, dimensão da vida que se marca pela experiência. Como espaço de dimensões objetivas e subjetivas, o cotidiano é lugar da constituição dos laços e da sociabilidade, tornando-se palco de uma teatralidade com cenas, atores e enredos que se repetem e se renovam (GUIMARÃES, 2006). Ou seja, o cotidiano já está preparado para receber intervenções artísticas e comunicacionais, conservando-se como forma capaz de articular o estar em um mundo aberto, em fluxo, permanentemente construído no entremear de imagens, falas, tradições e saberes.

Michel Maffesoli (apud Maia, 2005) afirma que a sinergia entre o espaço e a sociabilidade cria um mundo original a partir da relação que a pessoa estabelece com o outro. Este mundo está em permanente formação e se constitui em um conjunto de referências partilhadas. O autor acentua a importância do mundano na formação de nossas sociedades, a grandeza e o trágico contidos no cotidiano e propõe uma intensiva aproximação com o objeto de pesquisa - o espaço urbano - 
sempre em movimento. Ocupamos um espaço material, constituído por ruas, monumentos e trânsito, ao mesmo tempo em que constituímos o espaço imaterial a partir das imagens de diversas ordens. Nestes dois pontos a ordem do simbólico é criada, a partir da circulação das informações, das coisas, das palavras e de tudo aquilo que faz parte de processos comunicativos e de sociabilidades. Ver e analisar de forma distanciada os fatos que constituem o social, não é suficiente. Metodologicamente, Maffesoli revela o aspecto tátil cada vez mais necessário na construção de qualquer objeto de pesquisa na sociedade contemporânea.

Essa aproximação também é proposta por artistas que desenvolvem seus trabalhos em meio aos fenômenos urbanos. E suas inserções nas dinâmicas cotidianas das cidades proporcionam um diálogo e uma contaminação contínua, que fazem da experiência algo em constante construção.

\section{Considerações Finais}

A diluição da distinção entre produção e recepção, evidencia a imprecisão das fronteiras entre as categorias artísticas, categorias comunicacionais e campos da experiência. Essa indefinição implica principalmente a transformação do papel do espectador, que segundo Rancière (2005), deve converter-se em agente de uma prática coletiva. Em acordo com essa ideia, Bourriaud (2006) recorre ao termo interstício social, que se configura como um espaço para as relações humanas que sugere possibilidades de intercâmbio.

Algumas instalações interativas, como as desenvolvidas por Rafael Lozano-Hemmer, propõem conjuntos articulados, multiplicados, agenciados, organizados no espaço e no tempo. A situação que surge a partir do confronto entre sistema e espectador em determinados espaços resulta em um deslocamento do foco de atenção. Isso acontece porque a estrutura da recepção que foi criada, apesar de ser controlada 
por dispositivos, permite uma abertura comportamental e criativa.

A pedagogia dos dispositivos de hoje se difere daquela pedagogia típica da modernidade, que ensinava os espectadores como reagir às imagens, como se comportar e seguir uma disciplina no ambiente da recepção, tendo o cinema como modelo. O importante aqui é reforçar que estas interações só são possíveis porque existe um cenário favorável a esse tipo de dinâmica. Um cenário marcado por transformações nos processos de subjetivações e por avanços técnicos. Um cenário marcado por novos padrões de consumo e novos padrões comportamentais. Enfim, um cenário marcado por novos propósitos artísticos e comunicacionais.

\section{Referências}

Bourriaud, N (2006). Estética relacional. Buenos Aires: Adriana Hidalgo Editora.

De Certeau, M (2009). A invenção do cotidiano: artes de fazer. Petrópolis: Vozes.

Flusser, V (2008). O universo das imagens técnicas: elogio da superficialidade. São Paulo: Annablume.

Guimarães, C. G.; França, V. R.V. (orgs.) (2006). Na mídia, na rua. Belo Horizonte: Autêntica.

Lefebvre, H (2003). Levels and dimentions. In: E.L. Stuart \& E. Kofman (Eds.), Henri Lefebvre Key Writings. New York, London: Continuum.

Maia, J (2005). Michel Maffesoli e a cidade partilhada. Famecos, 26 (1), 12-21.

Rancière, J (2005). A partilha do sensível: estética e política. São Paulo: Editora 34. 